\title{
Assessment of Pre-Service Teacher Dispositions
}

\author{
Excelsior: Leadership in \\ Teaching and Learning \\ 2020, Vol. 13(1), 50-62 \\ (C) The Author 2020 \\ CC-BY 4.0 International \\ Reprints and permissions: \\ surface.syr.edu/excelsior \\ https://doi.org/10.14305/in \\ .19440413 .2020 .13 .1 .03 \\ nyacte.org
}

\section{(D) Elizabeth Bradley ${ }^{1}$, Patricia Isaac ${ }^{2}$, and Joseph King ${ }^{3}$}

\begin{abstract}
Measurement of pre-service teacher dispositions is an important part of teacher preparation programs. A strong correlation exists between dispositions of teachers and the quality of their students' learning. Teachers, in addition to sharing content knowledge, are responsible for demonstrating and sharing core values relating to virtues such as honesty, justice, fairness, care, empathy, integrity, courage, respect, and responsibility, and these values must guide their own conduct and interpersonal relations. As teachers serve pupils who are minors, their conduct and potential to serve effectively and ethically in the profession must be evaluated. However, a thorough faculty-led instrument to assess pre-service teacher candidates' disposition does not currently exist. The purpose of this research was to develop an assessment of pre-service teachers' dispositions for use in teacher education programs. A 25-item instrument was created through assessment of teacher education program needs and review of best practices on building teacher evaluation instruments, national professional teaching standards, and existing assessment tools. Teacher education faculty completed the instrument assessing roughly 600 teacher candidates in a masters-level teacher education program. Results indicate that this instrument is a valid and reliable tool that will allow teacher education faculty and administrators to assess teacher candidate professional skills and conduct.
\end{abstract}

\section{Keywords}

teacher education, preservice teacher, dispositions, assessment, psychometric properties

\footnotetext{
${ }^{1}$ SUNY Empire State College

2 SUNY Empire State College

${ }^{3}$ SUNY Empire State College

Corresponding Author:

Elizabeth Bradley, School for Graduate Studies, SUNY Empire State College, 21 British American Boulevard, Latham, NY 12110

Email: elizabeth.bradley@esc.edu
} 
Dispositions are predictive patterns of action, or individual tendencies to act in a given manner (Borko \& Whitcomb, 2007). InTASC (the Interstate New Teacher Assessment and Support Consortium) defines dispositions as "the habits of professional action and moral commitments that underlie an educator's performance" (InTASC, 2013, p. 6.). Teacher dispositions can greatly impact student learning, motivation, and development (Singh \& Stoloff, 2008). Teacher values, attitudes and beliefs affect student classroom experiences, and teachers who care about student success and achievements are willing to exert the extra effort to ensure that their classrooms are productive learning environments (Notar et al., 2009; Taylor \& Wasicksko, 2000). Teachers who possess dispositions most effective for student learning demonstrate qualities such as empathy, positive view of self, positive view of others, authenticity, and meaningful purpose and vision (Combs, 1999; Usher, 2002; Notar et al., 2009).

Measurement of pre-service teacher dispositions is an important part of teacher preparation programs (Phelps, 2006). As teacher candidates will serve pupils who are minors and thus a vulnerable population, teacher education faculty and administrators have an obligation to protect those pupils and cannot tolerate teacher candidate behavior that potentially threatens their welfare. Thus, teacher candidates must demonstrate values and attitudes consistent with the highest professional standards. Teachers, in addition to sharing content knowledge, are responsible for demonstrating and sharing core values relating to virtues such as honesty, justice, fairness, care, empathy, integrity, courage, respect, and responsibility, and these values as such must guide their own conduct and interpersonal relations (Notar et al., 2009).

Teacher candidate personal characteristics, conduct, potential to serve effectively and ethically in the profession, and advancement in teacher education programs must be evaluated. Disposition assessments are useful tools in gauging teacher candidate success in their professional capacities as teachers (Choi et al., 2016). While it may be agreed upon that teacher disposition has an effect on student learning and is an intangible that should be assessed similarly to content knowledge and other skills, there is subjectivity in the assessment constructs. While indicators such as empathy, caring and enthusiasm may be seen as qualities of a positive teacher disposition, without identifying descriptors of the indicators, assessments are likely to be variable and subjective (Johnston et al., 2011).

Rike and Sharp (2008) discuss the importance of developing a research-based assessment tool for pre-service teacher disposition. Likewise, Johnston and colleagues (2011) developed nine researchbased indicators of teacher dispositions to help guide teacher education programs in the process of creating assessments of teacher disposition. An assessment framework allows faculty to convey disposition expectations to teacher candidates, identify dispositions as professional obligations, limit subjectivity in assessing dispositions, and impart to pre-service teacher candidates that who they are and what they believe has a long-lasting impact on their career and teaching effectiveness (Johnston et al., 2011). Assessments that allow educators to track teacher disposition as an essential professional obligation for effective teacher candidate learning serve as an early warning system, allowing for the documentation of problematic dispositions of pre-service teachers and resulting in expedited action when addressing inappropriate attitudes or behaviors (Johnston et al., 2011). However, a thorough faculty-led instrument to conduct this evaluation before teacher candidates begin teaching in the classroom does not currently exist. For this reason, this manuscript will discuss the development of a faculty-led assessment of pre-service teacher disposition. 


\section{National Teaching Standards}

Teacher education programs are responsible for establishing and maintaining a framework of performance assessments and standards for teacher candidates, as well as documenting competencies and dispositions related to effective instruction. Central to this framework are defined standards on appropriate assessments for academic and clinical settings (Almerico et al., 2011; Whaley, 1999) as requirements set forth by the Council for the Accreditation of Educator Preparation (CAEP), the National Middle School Association (NMSA), and the Interstate New Teacher Assessment and Support Council (INTASC). CAEP (2019) discusses teacher candidate professional knowledge, skills, and dispositions in standards one through four, focusing on the role that teacher candidate dispositions play in 1) content and pedagogical knowledge, 2) clinical partnerships and practice, 3) candidate quality, recruitment, and selectivity, and 3) program impact. Standard three directs educator preparation programs to

establish and monitor attributes and dispositions beyond academic ability that candidates must demonstrate at admissions and during the program. The provider selects criteria, describes the measures used and evidence of the reliability and validity of those measures, and reports data that show how the academic and non- academic factors predict candidate performance in the program and effective teaching (CAEP, 2019, standard 3.3)

While accrediting agencies recognize the importance of teacher dispositions as they relate to student learning, how to specifically measure the elements, traits, or qualities composing target dispositions is not clearly outlined (Johnston et al., 2011). Similarly, while The National Board for Professional Teaching Standards (NBPTS) defines five propositions that form the basis of all National Board Standards and implies the importance of positive teacher dispositions, it lacks the specific language or guidelines for how to measure the qualities or traits that make up effective teacher dispositions (NBPTS, 2016).

Teacher educators are faced with the challenge of effectively evaluating a teacher candidate's disposition as it relates to classroom instruction. The teacher candidate may meet all program requirements and pedagogical skills, but that does not guarantee a successful instructional implementation in the classroom (Almerico et al, 2011). The manner in which knowledge is shared with students in the classroom is the way learning is facilitated and, as such, teacher disposition and disposition training and assessment are integral (Johnston et al., 2011). Wasiscsko, Director of the National Network of the Study of Educator Disposition, concurs:

One of the most difficult situations faced by teacher educators is encountering students who clearly lack the dispositions necessary to be successful educators but meet all other requirements... To address the ethical and legal concerns, teacher educators must have a research-based rationale for the dispositions-related outcomes of candidates and graduates as well as a methodology by which to assess these outcomes (2020, para.2).

In addition to assessing teacher readiness, dispositional assessments can also provide useful feedback to teacher candidates throughout their degree program. Anderson and Brydges (2011) had teacher candidates and their supervisors collect dispositional assessment data in order to facilitate discussion and feedback of areas of strength and weakness. They found a statistically significant increase in teacher candidate dispositional scores over time, which Anderson and Brydges (2011) attributed to the consistent formative assessment and feedback provided to teacher candidates by their 
supervisors. Likewise, our intention with the development of this assessment of pre-service teacher disposition is to allow a vehicle for program faculty to provide useful feedback and supervision regarding any areas of weakness that teacher candidates may display.

\section{Teacher Candidate Self-Assessment Tools}

A review of literature on building teacher evaluation instruments, National Board for Professional Teaching Standards, National Council for Accreditation of Teacher Education Professional Standards, and current instruments that other teacher education programs utilize informed the development of this instrument. Singh and Stoloff (2008) developed the Eastern Teacher Disposition Index (TDI), which is a 46-item Likert scale in which teacher candidates self-assess perceptions about themselves, others, their subject field, and the purpose of education and the process of learning. Findings of the study indicate that Eastern teacher candidates appear to have dispositions of effective teachers and that their perceptions are overwhelmingly positive with room for improvement in collaboration and problemsolving skills.

Schulte and colleagues (2004) developed and validated the Teacher Disposition Index, which is aligned with the dispositions specified under the Interstate New Teacher Assessment Consortium (INTASC; 1992) Model Standards for Beginning Teacher Licensing and Development. The TDI is a 45-item instrument that includes two subscales: 1 ) student-centered (25 items) and 2) professionalism and curriculum-centered ( 20 items). The authors reported that the TDI is a reliable and valid instrument for measuring the dispositions of effective teachers. In addition, they concluded that the TDI will be a useful tool for teacher candidate self-reflection and a vehicle for teacher education faculty to incorporate dispositional topics into coursework and program assessment.

Pang and colleagues (2014) developed a 21-item assessment tool entitled the Teacher Disposition Checklist (TDC), which is based on the previously mentioned guidelines developed by Johnston and colleagues (2011). They identified five teacher dispositions deemed most relevant to the growth and development of teacher candidates by program faculty: 1) upholding professional and ethical standards, 2) embracing diversity, 3) engaging in collaborative endeavors, 4) reflecting and problem solving, and 5) valuing life-long learners (Pang et al., 2014). Recommendations for the use of the TDC including increased specificity with individual item language to ensure that the behaviors being evaluated are explicit (Pang et al., 2014).

An additional self-assessment of teacher candidate dispositions was developed by DePaepe and colleagues (2010). The authors developed an inventory for teacher candidates as they progressed through their education program. The scale assesses four domains: scholarly and collaborative pursuit, instilling lifelong learning in their teacher candidates, becoming self-reflective practitioners, and recognizing the responsibility to support learners. Results indicated that teacher candidates scored higher upon graduation than they did during their first year in the program, and strong internal consistency and validity were also demonstrated (DePaepe et al., 2010).

\section{Student Teaching Disposition Assessments}

Choi and colleagues (2016) developed an assessment of teacher candidate dispositions for those already teaching in the classroom. This 19-item rating form was completed by university and field supervisors as they were observing teacher candidates in the K-12 classroom. The form measured six 
professional dispositions: responsibility, respect, integrity, caring/humanity, fairness, and the belief that all students can learn. The measure was found to have strong internal consistency but lacked predictive validity in teacher candidates' ability to engage students in the classroom (Choi et al., 2016).

Nweke and colleagues (2019) also developed a disposition assessment to be utilized during student teaching. The Candidate Dispositions Performance Assessment Rubric (CDPA) assesses teacher candidate disposition across 24 themes that align with INTASC standards. Nweke and colleagues also developed a student-self assessment tool to be used in tandem with the CDPA. These instruments demonstrated a high level of internal consistency and inter-rater reliability and are complementary when utilized together (Nweke, 2019).

The assessment tools reviewed demonstrated strong psychometric properties and measured important teacher characteristics. However, none were closely aligned with the National Board for Professional Teaching Standards (2016) and Council for the Accreditation of Educator Preparation (CAEP) standards (2019). In addition, we desired an instrument that would be completed by program faculty rather than utilized solely as a teacher candidate self-assessment tool to eliminate teacher candidate self-bias, as there is some evidence that student self-assessments are significantly different than faculty ratings (Ignico \& Gammon, 2010). The existing tools were intended for teacher candidate self-assessment or for use in a student teaching setting, rather than for the intended purpose of assessing teacher candidates prior to entering the classroom.

\section{Study Purpose}

The purpose of this research was to develop an assessment of pre-service teacher dispositions for use in a master's-level teacher education program. This instrument will allow teacher education faculty and administrators to assess teacher candidate professional skills and conduct, and to provide a vehicle for feedback to teacher candidates based on assessment results.

\section{Method}

\section{Subjects}

A total of 16 teacher education faculty completed the instrument assessing roughly 600 teacher candidates in a master's-level teacher education program. This program is located in the Northeast region of the United States and the MAT program is an alternative certification program that takes teacher candidates two to three years to complete. Faculty were a mix of new and veteran faculty and they completed the assessment tool for all teacher candidates in the Master of Arts in Teaching Program who they taught each term at the end of the term. Data were collected over a three-year period. Teacher candidate subject areas included science, English, LOTE (languages other than English), math, and social studies and the certification level was middle childhood to adolescent. No vulnerable populations were used.

\section{Survey Development}

The instrument was created through assessment of teacher education faculty and administrator needs. Survey items were developed through a review of relevant literature regarding best practices on 
building teacher evaluation instruments, national professional teaching standards, and existing assessment tools of pre-service teacher professionalism, dispositions, and caring-teaching skills (Bitner \& Kratzner, 1995; National Board for Professional Teaching Standards, 2016; CAEP, 2019; NowakFabrykowski, 2011; Poole \& Wessner, 2003; Schulte et al., 2004; Singh \& Stoloff, 2008). In addition, care was taken to measure dispositions rather than other teacher characteristics related to knowledge and skills (Bair, 2017).

Bitner and Kratzner (1995) raise important criteria such as that scale items should be clearly related to student learning and should be stated positively and in overtly behavioral terms to assist with reliable measurement of constructs. To aide with validity and reliability, we attempted to limit each scale item to the measurement of one type of behavior. Bitner and Kratzner (1995), in their primer on building a scientifically oriented teacher evaluation instrument, stress the importance of accurate, and thus scientific, measures of teacher candidate performance. The authors discuss the concepts of validity and reliability, which are crucial in instrument development, and they offer criteria for a scientifically based evaluation instrument: 1) Can the items on the instrument evaluate effective teacher practice and 2) Can we be certain that the instrument gives accurate results (Bitner \& Krazzner, 1995)?

We outlined the National Board for Professional Teaching Standards (2016) recommendations for teachers and developed scale constructs and items that reflected each of their teaching standards. The standards related to commitment, responsibility, and reflection (standards 1,3 , and 4) were not measured by the classroom observation rubrics utilized with pre-service teachers and thus seemed to be important to include. Constructs from other assessment tools served as a jumping off point for scale constructs and items, and the assessment went through several iterations, with additions and deletions from faculty, and the overall scale went from seven to five constructs through combining like items.

\section{Survey Attributes}

The survey consists of 25 items and includes five sections (see Figure 1). Items are scored using a fourpoint Likert scale (strongly disagree to strongly agree). The term "student" in the survey items refer to teacher candidates, as they are students in the courses who the faculty completing the survey teach. Below are examples of one scale item from each section:

- Responsibility: The student completes assignments and other course responsibilities.

-Integrity: The student displays sensitivity to social, cultural, ethnic, and religious differences.

-Enthusiasm: The student accepts feedback and works to improve his or her skills.

-Communication: The student is a thoughtful and responsive listener in course discussions and meetings.

-Reflection: The student connects prior knowledge and new information.

\section{Data Collection and Analysis}

Program faculty were asked to complete the instrument for each teacher candidate in their courses, using their first-hand knowledge of the teacher candidates. All faculty had previously received training in the disposition assessment, including a norming session with case studies, rating comparisons, and a faculty discussion of scoring practices. Faculty were recruited through an email, which contained a link to the online survey. 
Figure 1

Bradley-Isaac Assessment of Pre-Service Teacher Disposition

Instructions: Rate each item on a scale of 1 to 4, 1 = strongly disagree, $2=$ disagree, $3=$ agree, $4=$ strongly agree, and $\mathrm{n} / \mathrm{a}=$ no basis for judgment

\section{Responsibility}

The student attends class regularly

The student arrives to class on time

The student completes assignments and other course responsibilities

The student assumes responsibility when working with others

The student meets work submission deadlines

The student keeps scheduled appointments with program faculty

Integrity

The student completes his or her own work

The student gives credit to others' work using APA formatted citations and references

The student adheres rigorously to the college's guidelines for academic integrity (http://www.esc.edu/academicintegrity)

The student displays sensitivity to social, cultural, ethnic, and religious differences

The student treats faculty and staff respectfully

The student treats peers respectfully

\section{Enthusiasm}

The student demonstrates a desire to learn

The student shows concern for mastery of material

The student shares knowledge with the class

The student accepts feedback and works to improve his or her skills

\section{Communication}

The student clearly articulates ideas verbally and in written expression

The student uses correct spelling, grammar, and punctuation

The student uses appropriate language in online discussions, emails, and course meetings

The student communicates in a logical and organized manner

The student is a thoughtful and responsive listener in online discussions and course meetings

The student maintains emotional control

\section{Reflection}

The student demonstrates the characteristics of a reflective practitioner in course discussions, assignments, and meetings

The student connects theory with practice

The student connects prior knowledge and new information
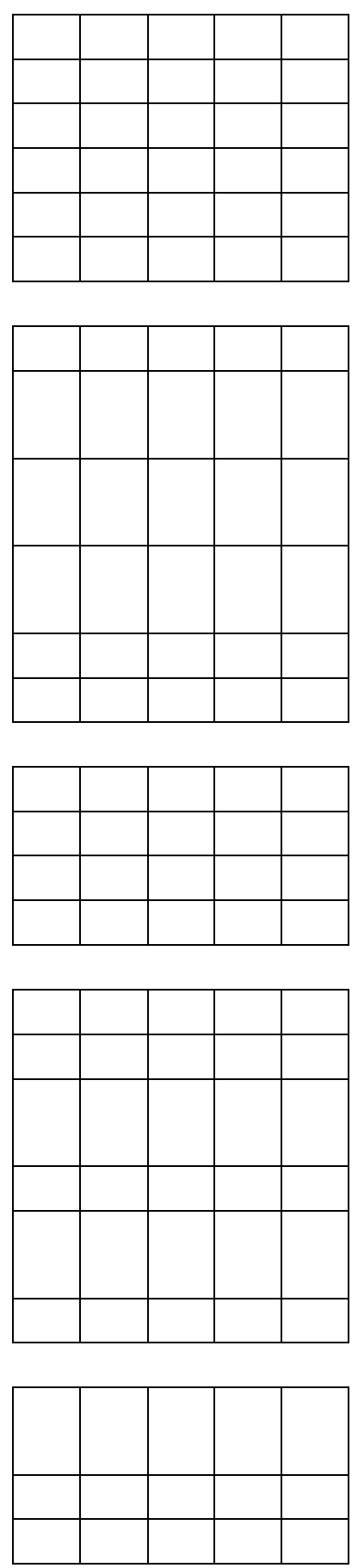
The survey contained the informed consent letter, which included information on the purpose of the survey and how the data will be utilized. Neither faculty nor teacher candidates received any incentive or compensation for study participation, and they were assured that whether or not they participated in the study would remain confidential from other program faculty and administrators. Data were exported directly from Survey Monkey to Excel and analyzed using SPSS.

Additional data collected includes a survey sent to colleagues at other college campuses with MAT programs; faculty and administrators were assessed utilizing the Lawshe method to analyze instrument content validity (Lawshe, 1975). For this assessment, we surveyed experts (teacher education program administrators at nearby colleges) on the assessment tool items, asking about their utility. The survey consisted of three possible ratings per assessment item: 1) essential, 2) useful, but not essential or 3) not useful. Participants were recruited via email and then directed to a consent form and survey in survey monkey. Data were exported directly from Survey Monkey to Excel and analyzed using SPSS.

\section{Results}

Internal consistency was used as a measure of reliability, to assess how well the scale items that make up each construct, as well as the scale as a whole, hold together statistically (see Table 1). The statistic utilized to determine internal consistency is Cronbach's alpha, and levels of 0.70 or higher demonstrate strong reliability for new scale development. Cronbach's alpha for the scale constructs are below and demonstrate excellent reliability at levels of 0.90 and above. Thus, each of the scale constructs, as well as the scale as a whole, are closely related.

Table 1

Internal consistency of scale constructs

\begin{tabular}{llll}
\hline Construct & $\mathrm{N}$ & Items & Cronbach's alpha \\
\hline Responsibility & 222 & Items 1-6 $(\mathrm{n}=6)$ & 0.913 \\
Integrity & 614 & Items 7-12 $(\mathrm{n}=6)$ & 0.954 \\
Commitment & 634 & Items 13-16 $(\mathrm{n}=4)$ & 0.927 \\
Communication & 622 & Items 17-22 $(\mathrm{n}=6)$ & 0.945 \\
Reflection & 635 & Items 23-25 $(\mathrm{n}=3)$ & 0.934 \\
\hline
\end{tabular}

When comparing total scale scores across teacher candidates, there were no statistically significant differences between gender and only two of 25 items showed statistically significant differences by subject area being taught. This suggests that all teacher candidates are being scored similarly by teacher education faculty regardless of gender and subject area.

Several measures of predictive validity were evaluated utilizing two-tailed independent samples ttests, with equal variances not assumed. We hypothesized that teacher candidates with higher total scale scores would have higher GPAs than teacher candidates with lower scale scores. Teacher candidates with a GPA of 4.0 were compared with those of lower GPA, and differences in their overall scale scores were significant at the .001 level. Thus, our hypothesis was confirmed and results provided evidence for scale predictive validity, as well as a strong relationship between scale constructs and GPA as a performance indicator of overall academic success.

Four MAT program administrators participated in the content validity assessment utilizing the 
Lawshe method. Results indicated that all survey items were rated as either essential or useful, indicating strong content validity. Mean item ratings and content validity ratios (CVRs) are included in Table 2. The mean CVR for the instrument as a whole is .81, which is above the threshold established by Polit and colleagues (2007), indicating that an instrument with a CVR of .78 or higher by three or more raters is considered to be strong content validity.

Table 2

\section{Content Validity Results}

\begin{tabular}{lll}
\hline Survey item & Mean & CVR \\
\hline The student attends class regularly & 3.00 & 1.0 \\
The student arrives to class on time & 2.75 & .75 \\
The student completes assignments and other course responsibilities & 3.00 & 1.0 \\
The student assumes responsibility when working with others & 3.00 & 1.0 \\
The student meets work submission deadlines & 3.00 & 1.0 \\
The student keeps scheduled appointments with program faculty & 2.75 & .75 \\
The student completes his or her own work & 3.00 & 1.0 \\
The student gives credit to others' work... & 2.50 & .50 \\
The student adheres rigorously to the college's guidelines for academic integrity & 3.00 & 1.0 \\
The student displays sensitivity to social, cultural, ethnic, and religious differences & 3.00 & 1.0 \\
The student treats faculty and staff respectfully & 3.00 & 1.0 \\
The student treats peers respectfully & 3.00 & 1.0 \\
The student demonstrates a desire to learn & 2.75 & .75 \\
The student shows concern for mastery of material & 2.25 & .25 \\
The student shares knowledge with the class & 2.25 & .25 \\
The student accepts feedback and works to improve his or her skills & 2.75 & .75 \\
The student clearly articulates ideas verbally and in written expression & 3.00 & 1.0 \\
The student uses correct spelling, grammar, and punctuation & 2.75 & .75 \\
The student uses appropriate language... & 3.00 & 1.0 \\
The student communicates in a logical and organized manner & 2.75 & .75 \\
The student is a thoughtful and responsive listener... & 2.75 & .75 \\
The student maintains emotional control & 2.75 & .75 \\
The student demonstrates the characteristics of a reflective practitioner & 2.50 & .50 \\
\hline The student connects prior knowledge and new information & 3.00 & 1.0 \\
\hline Note. $M$ & 2.75 & .75 \\
\hline
\end{tabular}

Note. ${ }^{*}$ Mean item scores on a scale of 1 = not important, 2 = useful but not essential, 3 = essential;

${ }^{* *} \mathrm{CVR}=\left(\mathrm{N}_{\mathrm{e}}-\mathrm{N} / 2\right) /(\mathrm{N} / 2) ; \mathrm{N}_{\mathrm{e}}=$ number of reviewers indicating "essential," $\mathrm{N}=$ total reviewers 


\section{Discussion}

Results point to strong reliability and validity of this scale as a measure of pre-service teacher disposition. This assessment has been implemented by program faculty for all teacher candidates in the Master of Arts in Teaching Program each term since 2012. Though initially completing the assessment for all teacher candidates taught each term was a workload concern for faculty, the benefits have far outweighed the costs. The assessment has become part of the program teacher disposition policy (SUNY, 2010), which appears in the graduate catalog, and has helped expectations become more transparent for teacher candidates.

Teacher candidates who receive a 2 or less on any scale item are flagged by the MAT program director for further review. Roughly $25 \%$ of teacher candidates are flagged each term for scoring 2 or less on any survey item. Teacher candidates and their advisors receive a letter with information about the concerns expressed in the assessment, and the advisor, program director, and course instructor triage in the event of serious concerns. A formal professional dispositions improvement plan was developed for the teacher candidate and advisor to complete together when teacher candidates are flagged based on low assessment scores. The improvement plan takes teacher candidates though planning for continuous improvement, identification of the indicators of continuous improvement, and a proposed timeline for continuous improvement.

Once the specific benchmarks outlined in the plan are achieved, the need for further action is evaluated. True to the recommendations of Notar and colleagues (2009), this information is saved in program records for future reference, so that teacher candidate progress can be easily tracked over time. If necessary, a mechanism exists through the program's Policy on Professional Expectations to dismiss teacher candidates who display persistent and long-term serious dispositional issues, which is also a recommendation by Notar and colleagues (2009). Overall, implementation of the assessment, as well as the improvement plan, has been very positive and has enriched advisee-advisor communication as well as teacher candidate growth and development.

Limitations of this research include a small sample size for the content validity analysis, as well as the lack of faculty and teacher candidate demographic information. Future data collection could add these demographic questions to allow for analysis of the potential impact of the age of the assessor and pre-service candidate. Additional future analyses of the disposition survey data may include inter-rater reliability between faculty members as well as the social validity of the measure, including the feasibility of completing the scale for each teacher candidate in each course a faculty member teaches, given other workload demands. Teacher candidate self-assessments have also been completed, and inter-rater reliability could be calculated between teacher candidate and faculty scale scores. Nweke and colleagues (2019) conducted a similar analysis with their Candidate Dispositions Performance Assessment Rubric (CDPA) and the Candidate Beliefs Self-Assessment Survey (SAS) with positive results.

In this study, we did not collect teacher candidate perceptions of the disposition assessment process. However, we did collect teacher candidate comments in their self-assessment, asking why they rated themselves with a score of 2 or lower in any category if applicable. Their responses provided some insight into important considerations in the assessment process. One teacher candidate wrote that he is still working on time management, but all of his "needs/requests for extra time fall within reasonable accommodations under the ADA." This brings up the importance of faculty considering teacher candidate disability accommodations as they complete the disposition assessments. Another 
teacher candidate who also has difficulty with time management wrote: "Sometimes it is hard to meet deadlines in my current situation, as I manage the needs of my family and elders and those of my degree program." This comment reflects our unique teacher candidate population, as our MAT program includes many teacher candidates who are career changers and have families and full-time jobs while completing the program. Thus, their disposition assessment results may change as their responsibilities and life stressors ebb and flow.

Al-Rawashdeh and colleagues (2017) evaluated the experiences of teacher candidates undergoing disposition assessments and have several recommendations for best practice, based on teacher candidate feedback: ensure that all instructors are trained in the disposition assessment, follow-up with teacher candidates with a plan for improvement and monitor their progress, provide feedback with the disposition assessment score, and allow teacher candidates a forum to discuss disposition development. Our MAT program incorporates training and a plan for continuous improvement, but allowing teacher candidates discussion of disposition assessment is a solid next step; all of these practices are considerations in disposition assessment implementation.

Results indicate that this instrument is a useful tool that will allow teacher education faculty and administrators to assess teacher candidate professional skills and conduct. It is our hope that this scale will continue to serve as a vehicle for program faculty to assess the performance of pre-service teachers, provide at-risk teacher candidates with feedback and support in any areas of weakness. Some of the most effective methods for enhancing teacher dispositions include providing field experiences with quality mentors, utilizing case studies, developing collegial relationships among teachers and school districts, fostering multicultural education, and promoting teacher candidate self-efficacy (Whitley, 2011). In addition, this assessment tool will also enable teacher candidates the opportunity for selfassessment in their "goodness of fit" with teaching as an occupation as well as growth in their teaching dispositions.

\section{Declaration of Conflicting Interests}

The author declared no potential conflicts of interest with respect to the research, authorship, and/or publication of this article.

\section{Funding}

The authors received no financial support for this research.

\section{ORCID iD}

Elizabeth Bradley (ID https://orcid.org/0000-0002-3989-6452

\section{References}

Almerico, G.M., Johnston, P., Henriott, D., \& Shapiro, M. (2011). Dispositions assessment in teacher education: Developing an assessment for the college classroom. Research in Higher Education Journal, 11, 1-19.

Al-Rawashdeh, A., Ivory, G., \& Writer, J.H. (2017). Evaluating the dispositions of teacher education candidates: A place for self-assessment. Journal of Educational and Psychological Studies, 11(4), 749-761. http://doi.org/10.24200/ieps.vol11iss4pp749-761 
Anderson, D. L., \& Brydges, B.C. (2011). Professional teaching dispositions for elementary versus middle/secondary: Testing the generalizability of findings from rubric assessment data to identify and improve performance of struggling and high risk teacher candidates. International Journal of Arts and Sciences, 4(11), 253-268.

Bair, M.A. (2017). Identifying dispositions that matter: Reaching for consensus using a Delphi study. The Teacher Educator, 52(3), 222-234. https://doi.org/10.1080/08878730.2017.1315475

Bitner, T. \& Kratzner, R. (1995). A primer on building teacher evaluation instruments [Conference presentation]. Annual Meeting of the Midwest Educational Research Association. Chicago, IL, United States. (ERIC No. ED394953).

Borko, H., Liston D., \& Whitcomb, J. (2007). Apples and fishes: The debate over dispositions in teacher education. Journal of Teacher Education, 58(5), 359-364. https//doi.org/10.1177/0022487107309977

Council for the Accreditation of Educator Preparation (2019). Standard 3. Candidate quality, recruitment, and selectivity. http://caepnet.org/standards/standard-3

Choi, H., Benson, N.F., Shudak, N.J. (2016). Assessment of teacher candidate dispositions. Teacher Education Quarterly, 43(3), 71-89.

Combs, A. W. (1999). Being and becoming: A field approach to psychology. Springer.

DePaepe, J., Lambert, C., Curran, C., \& Shorr, D. (2010). Assessing teacher candidate dispositions. Northwest Passage: Journal of Educational Practices, 1(8), 9-30.

Ignico, A., \& Gammon, K. (2010). A longitudinal study of the professional dispositions of teacher candidates. Natural Science, 2,91-94. https://doi.org/10.4236/ns.2010.22014

Interstate New Teacher Assessment and Support Consortium (INTASC; 1992). Model standards for beginning teacher licensing and development. Council of Chief State School Officers.

Interstate New Teacher Assessment and Support Consortium (INTASC; 2013). INTASC model core teaching standards and learning progressions for teachers 1.0. Retrieved from https://ccsso.org/sites/default/files/201712/2013 INTASC Learning Progressions for Teac hers.pdf

Johnston, P., Almerico, G.M., Henriott, D., \& Shapiro, M. (2011). Descriptions of dispositions for assessment in pre-service teacher education field experiences. Education 132(2), 391-401.

Lawshe, C.H. (1975). A quantitative approach to content validity. Personnel Psychology, 28, 563575. https://doi.org/10.1111/j.1744-6570.1975.tb01393.x

National Board for Professional Teaching Standards. (2016). What teachers should know and be able to do. http://accomplishedteacher.org/wp-content/uploads/2016/12/NBPTS-WhatTeachers-Should-Know-and-Be-Able-to-Do-.pdf

Notar, C., Riley, G. \& Taylor, P. (2009). Dispositions: Ability and assessment. International Journal of Education 1(1), 2-14.

Nowak-Fabrykowski, K. (2011). An analysis of caring behaviour among teachers and children. Early Child Development and Care, 182(9), 1185-1192. https://doi.org/10.1080/03004430.2011.602192

Nweke, W.C., Perkins, T.P, Afolabi, C.Y. (2019). Reliability analysis of complementary assessment tools for measuring teacher candidate dispositions. Georgia Educational Researcher, 16(2), 133. https://doi.org/10.20429/ger.2019.160202 
Pang, Y., Nichols, K., Terwilliger, C., Walsh, M. (2014). Assessment of pre-service teachers' dispositions for programmatic improvement. National Teacher Education Journal, 7(1), 5360.

Phelps, P. (2006). The dilemma of dispositions. Clearing House, 79(4), 174-178. https://doi.org/10.3200/TCHS.79.4.174-178

Polit, D., Beck, C., \& Owen, S. (2007). Is the CVI an acceptable indicator of content validity? Appraisal and recommendations. Research in Nursing and Health, 30(4), 459-467. https://doi.org/10.1002/nur.20199

Poole, J. \& Wessner, J. (2003). The transition from student to teacher: Developing a self- assessment culture for professionalism in teacher preparation programs [Paper presentation]. Annual Meeting of the PAC-TE Teacher Education Assembly. Grantville, PA, United States. (ERIC No. ED481732).

Rike, C.J. \& Sharp, L.K. (2008). Assessing preservice teachers' dispositions: A critical dimension of professional preparation. Childhood Education 84(3), 150-153. https://doi.org/10.1080/00094056.2008.10522994

Schulte, L. E., Edick, N., Edwards, S., \& Mackiel, D. (2004). The development and validation of the teacher dispositions index. Essays in Education, 12(7). https://openriver.winona.edu/cgi/viewcontent.cgi?article=1078\&context=eie

Singh, D. K. \& Stoloff, D. L. (2008). Assessment of Teacher Dispositions. College Student Journal, 42(4), 1169-1180.

SUNY Empire State College (2010). MAT Policy on Professional Expectations. https://www.esc.edu/policies/?search=cid\%3D35647

Taylor, R.L. \& Wasicsko, M.M. (2000). The dispositions to teach. http://www.educatordispositions.org/dispositions/The Dispositions to Teach.pdf

Usher, D. (2002). Arthur Combs' five dimensions of helper belief reformulated as five dispositions of effectiveness [Paper presentation]. First Annual Symposium on Educator Dispositions: Effective Teacher-Effective Person. Richmond, KY, United States.

Wasiscsko, M.M. (2020). The national network for the study of educator dispositions. http://www.education.eku.edu/Dean/nnsedintro.htm

Whaley, D. C. (1999). Assessing the deposition of teacher education candidates. http://www.pearsonassessments.com/hai/images/NES Publications/1999 11Whaley 414 1.pdf

Whitley, C. (2011). Teacher dispositions. In B. Dore (Ed.), Keeping middle schools successful. National Association of Professors of Middle Level Education. http://www.napomle.org/KeepingMiddleSchoolsSuccessful/index. 